\title{
Expression of the Tomato Leaf Curl Geminivirus C4 Gene Produces Viruslike Symptoms in Transgenic Plants
}

\author{
L. R. Krake, M. A. Rezaian, and I. B. Dry \\ CSIRO Plant Industry, Horticulture Unit, PO Box 350, Glen Osmond, SA 5064, Australia \\ Accepted 14 January 1998.
}

\begin{abstract}
Transgenic tobacco and tomato plants expressing the $C 4$ gene from tomato leaf curl geminivirus (TLCV), under the control of the cauliflower mosaic virus $35 \mathrm{~S}$ promoter, developed virus-disease-like phenotypes. Plants transformed with a frame-shift version of the $C 4$ gene construct appeared normal but produced levels of transcript similar to those of plants expressing the $C 4$ gene. Thus, the abnormal plant phenotypes result from translation of the $C 4$ gene. These results support the hypothesis that the $\mathrm{C4}$ open reading frame of TLCV encodes a protein involved in the development of disease symptoms during viral infection.
\end{abstract}

Tomato leaf curl virus from Australia (TLCV; Dry et al. 1993) belongs to the Geminiviridae family (Briddon and Markham 1995), members of which are characterized by geminate particles containing circular, single-stranded DNA molecules ranging in size from 2.5 to $3.0 \mathrm{~kb}$, and are transmitted by whiteflies or by leafhoppers. The whiteflytransmitted geminiviruses (subgroup III) have either bipartite genomes consisting of two DNA species (A and B) or a monopartite genome. TLCV and a number of other viruses, which cause similar leaf curl diseases of tomato in different geographic regions, contain monopartite genomes that encode all of the functions necessary for a complete infection cycle (Navot et al. 1991; Kheyr-Pour et al. 1991; Dry et al. 1993; Noris et al. 1994; Hong and Harrison 1995).

The genomes of geminiviruses contain genes on both the virion-sense and complementary-sense strands of the replicative form of viral DNA. Mutagenesis studies on these open reading frames (ORFs) have shown that only one gene is indispensable for the replication of viral DNA (Elmer et al. 1988; Brough et al. 1988; Etessami et al. 1991). This gene, known as $C 1$ in monopartite viruses, or $A L 1$ or $A C 1$ in bipartite viruses, codes for the replication-associated protein (Rep) that initiates viral replication (Laufs et al. 1995). Another ORF known as C4 (AC4 or AL4) is contained entirely within the rep coding region but in a different reading frame.

Studies on the function of the C4 ORF have led to differing conclusions. In bipartite geminiviruses, mutagenesis of the AL4 ORF of tomato golden mosaic virus (Elmer et al. 1988;

Corresponding author: M. A. Rezaian; E-mail: ali.rezaian@pi.csiro.au
Pooma and Petty 1996), African cassava mosaic virus (Etessami et al. 1991), bean golden mosaic virus (Hoogstraten et al. 1996), and potato yellow mosaic virus (Sung and Coutts 1995), did not demonstrate any effect on viral replication or symptom development. This indicated AL4 ORF of these geminiviruses was nonfunctional in the hosts tested. In contrast, the $\mathrm{C} 4 \mathrm{ORF}$ of monopartite viruses appears to be functional. A C4 mutant of tomato yellow leaf curl virus (TYLCV), a virus similar to TLCV, was capable of autonomous replication but was unable to systemically infect tomato, suggesting that the $\mathrm{C} 4$ protein is involved in virus movement (Jupin et al. 1994). However, Rigden et al. (1994) did not find any evidence for a role of the C4 ORF of TLCV in systemic viral movement, but observed that it had a role in the development of viral symptoms in three different hosts. This was in agreement with previous results of mutagenesis studies with another monopartite geminivirus, beet curly top virus (BCTV), which indicated that the C4 ORF plays a significant role in the development of viral disease symptoms (Stanley and Latham 1992). In order to further test the role of the $C 4$ gene in symptom development, we have now produced transgenic tobacco and tomato plants expressing the viral $C 4$ gene and examined their phenotype in relation to viral symptom expression.

A DNA fragment encompassing the entire C4 ORF was amplified from pTLCV4 (Dry et al. 1993) with oligonucleotides (nucleotides 2466 to 2449 and nucleotides 2152 to 2172) incorporating HindIII and BamHI restriction sites at their respective $5^{\prime}$ ends. The polymerase chain reaction product was digested with HindIII and BamHI and cloned into pBluescript $\mathrm{SK}^{+}$(Stratagene, La Jolla, CA) to produce pBSC4. The integrity of the $\mathrm{C} 4 \mathrm{ORF}$ was confirmed by sequencing. The 306-bp fragment was released by enzyme digestion and subcloned into the expression vector pJIT163 (Guerineau et al. 1992). Digestion of the resultant plasmid with $B g l$ II yielded an expression cassette (approximately 1,300 bp) containing a tandem cauliflower mosaic virus (CaMV) $35 \mathrm{~S}$ promoter, C4 ORF, and CaMV 35S terminator. This cassette was cloned into BamHI-cut binary vector pBin19 (Bevan 1984) to give pBinC4 and electroporated into Agrobacterium tumefaciens strain LBA4404 for plant transformation.

Tobacco (Nicotiana tabacum cv. Samsun) was transformed with pBinC4, essentially by the method of Horsch et al. 

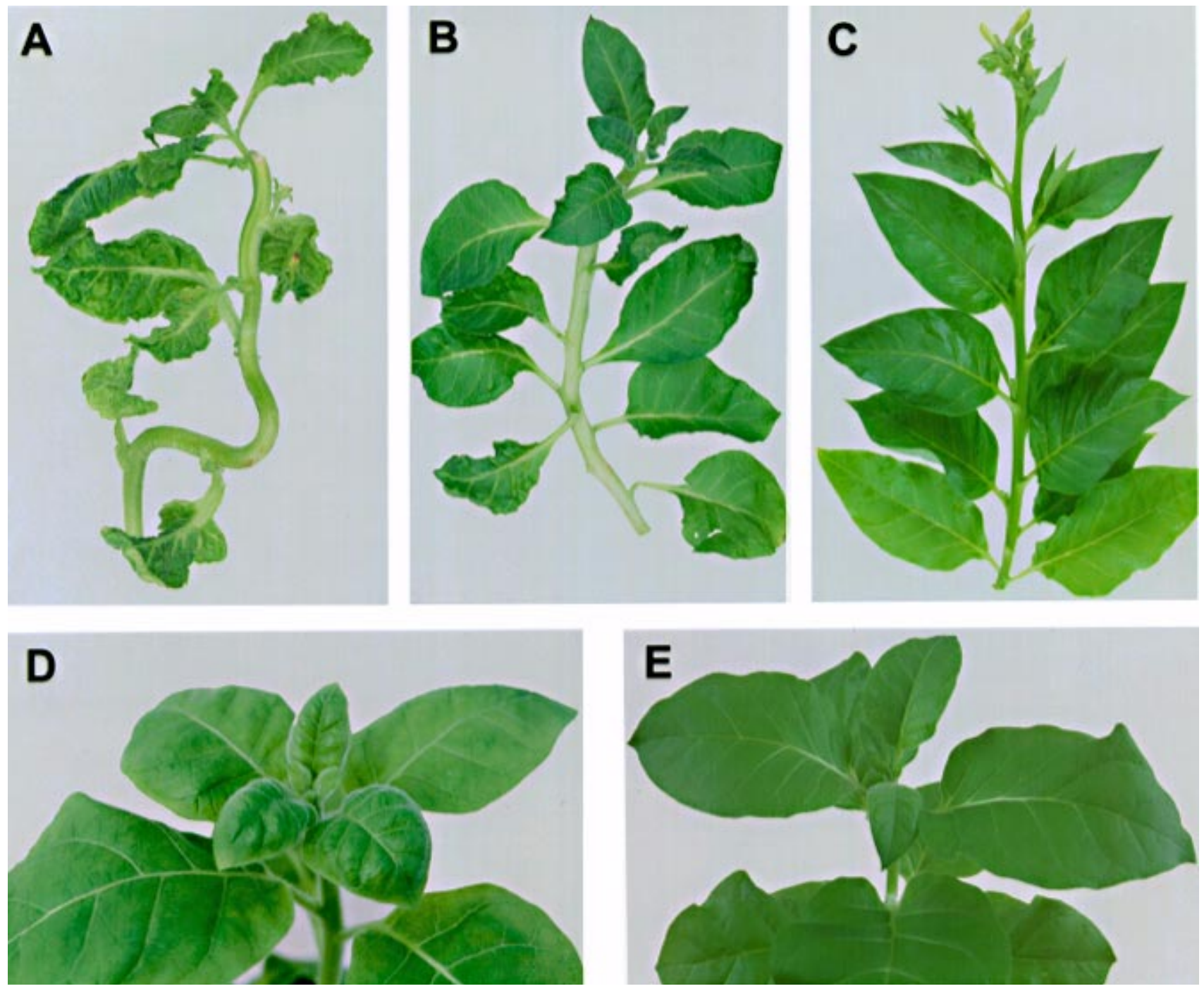

Fig. 1. Viruslike symptoms displayed by transgenic tobacco plants containing the tomato leaf curl geminivirus (TLCV) C4 gene. Examples of plants showing severe (A) and mild (B) symptoms are compared with the normal growth of plants transformed with a frame-shift version of the $C 4$ gene $(\mathbf{C})$. Shoots from a nontransgenic plant infected with wild-type TLCV (D) and a healthy plant (E) are also shown.

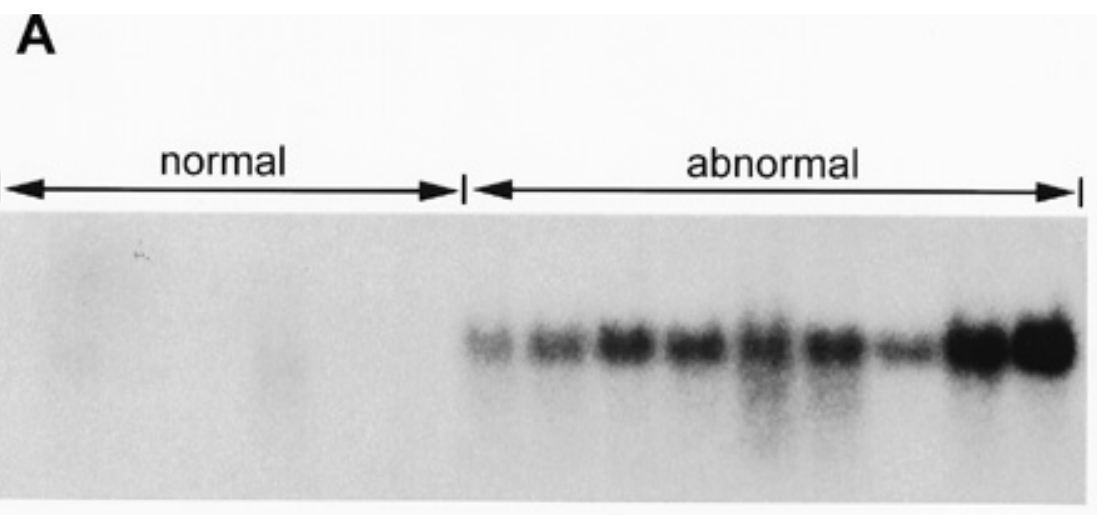

\section{B}

\section{$\begin{array}{llllllllllllllll}1 & 2 & 3 & 4 & 5 & 6 & 7 & 8 & 9 & 10 & 11 & 12 & 13 & 14 & 15 & 16\end{array}$}

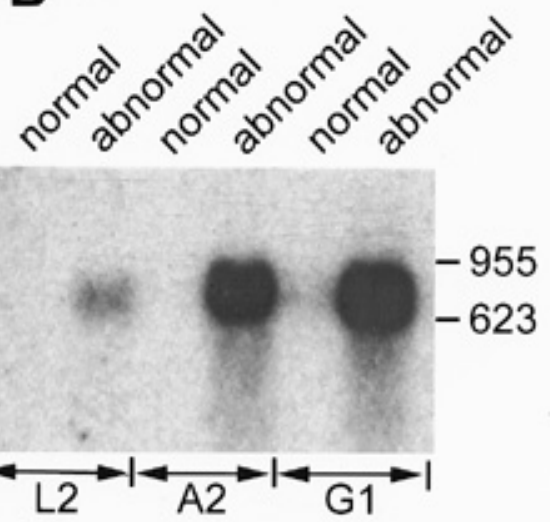

Fig. 2. RNA expression analysis of transgenic tobacco lines containing the tomato leaf curl geminivirus (TLCV) C4 gene. A, Total RNA (20 $\mu$ g per lane) was loaded from left to right on the basis of increasing severity of viruslike symptoms, fractionated through 1.5\% denaturing agarose (Sambrook et al. 1989), and blotted onto Zeta-Probe membrane (Bio-Rad, Richmond, CA) with 10× SSC buffer ( $1 \times$ SSC is $0.15 \mathrm{M} \mathrm{NaCl}$ plus $0.015 \mathrm{M}$ sodium citrate). Membranes were hybridized overnight at $65^{\circ} \mathrm{C}$ with a specific ${ }^{32} \mathrm{P}$-labeled probe prepared to a 1,630-bp fragment of pTLCV4 (incorporating the complementary-sense genes, nucleotides 1075 to 2643) with a GIGAprime Kit (Bresatec, Adelaide, Australia). Membranes were washed at room temperature in $2 \times \mathrm{SSC}, 0.1 \%$ sodium dodecyl sulfate (SDS) followed by two washes in $0.1 \times \mathrm{SSC}, 0.1 \%$ SDS at $65^{\circ} \mathrm{C}$ for 15 min each. The presence of radioactively labeled bands was detected by autoradiography. B, RNA extracts from normal and abnormal shoots taken from the same plant from three different $\mathrm{C} 4$ transgenic tobacco lines (L1, A2, and G1). RNA size markers are shown. 


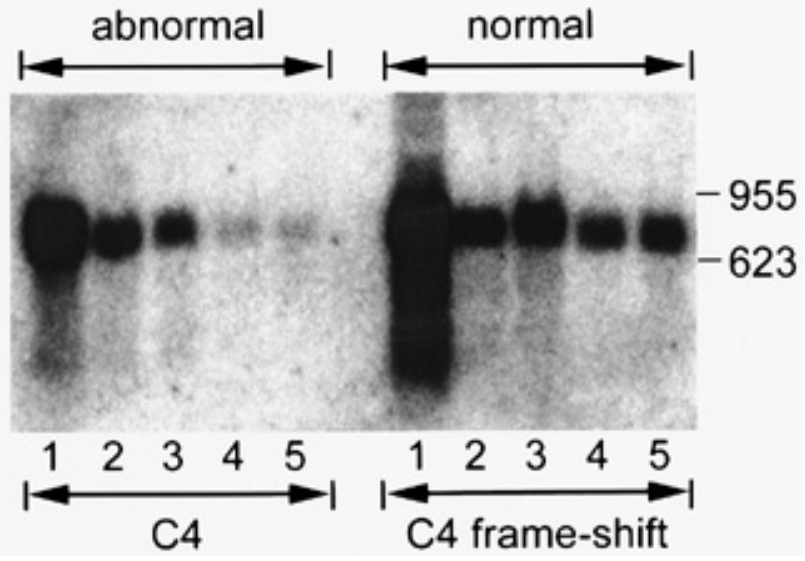

Fig. 3. Comparison of expression levels of the $\mathrm{C} 4$ and $\mathrm{C} 4$ frame-shift transcripts in transgenic tobacco lines. RNA extracts from five individual abnormal $\mathrm{C} 4$ plants were compared with examples from $\mathrm{C} 4$ frame-shift tobacco plants. RNA analysis as for Figure 2. RNA markers are shown.
(1985). Transgenic shoots were selected on kanamycin at a concentration of $250 \mu \mathrm{g} \mathrm{ml}^{-1}$ and grown at 25 to $27^{\circ} \mathrm{C}$ under artificial light $\left(150 \mu \mathrm{E} \cdot \mathrm{s}^{-1} \cdot \mathrm{m}^{-2}\right)$ for $16 \mathrm{~h}$ per day. During in vitro culture, it was observed that some of the shoots were severely deformed and failed to develop into plantlets. Of the 48 rooted plantlets produced, $35 \%$ appeared abnormal. A selection of 34 transgenic lines was transferred to potting soil and maintained in the glasshouse. The abnormal plants continued the development of deformed, stunted growth and produced viruslike symptoms on leaves. These symptoms included smaller than normal leaves, varying degrees of rugosity, blistering, twisting, curling of leaf margins, and mosaic patterns (the severe form shown in Figure 1A and mild form in Figure 1B). The upward curling of leaves was consistently displayed in all abnormal transgenic plants. Some plants showed proliferous growth with thickened stems and in severe cases zigzag growth (Fig. 1A).
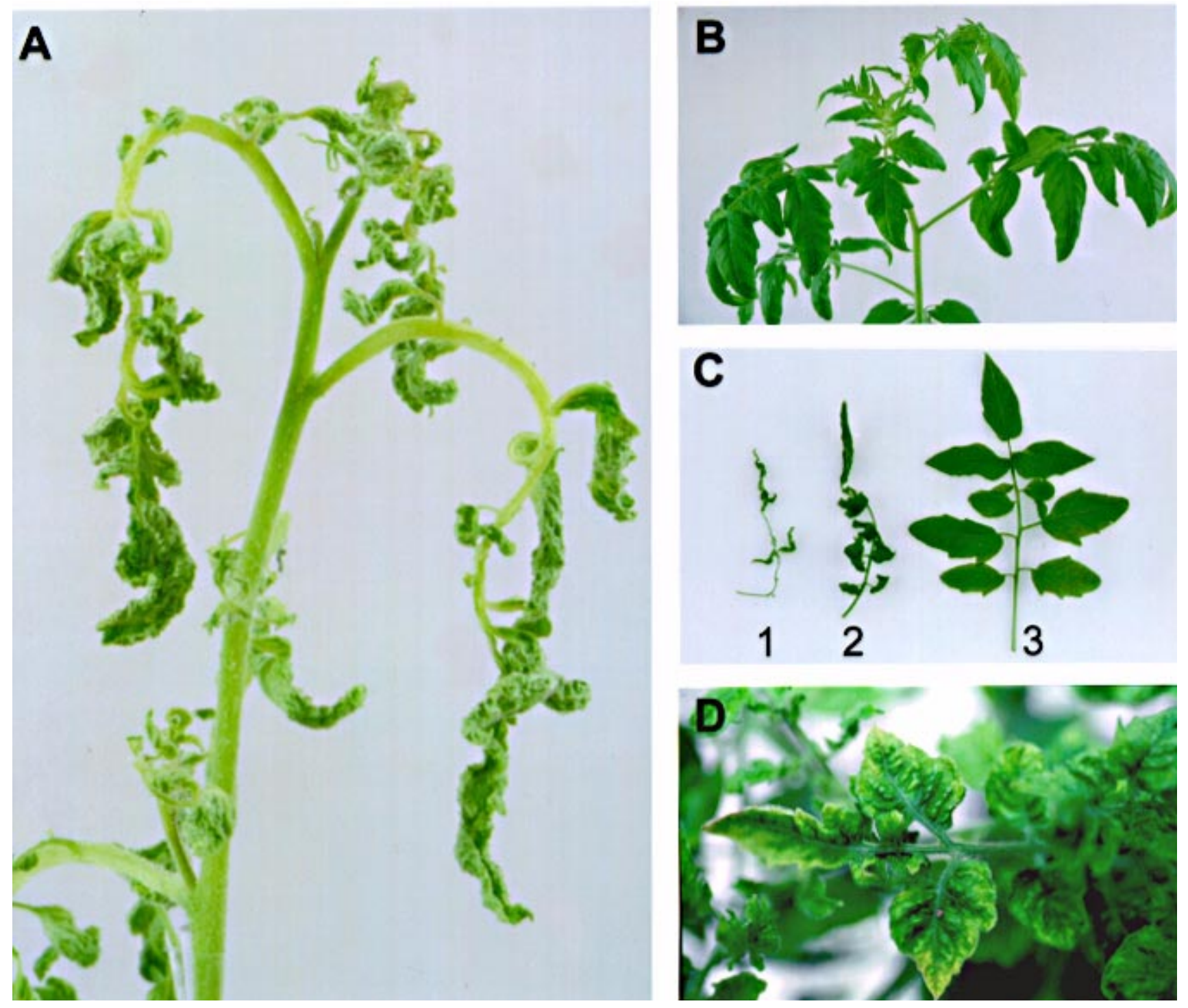

Fig. 4. Abnormal foliar symptoms induced in transgenic tomato plants expressing the $C 4$ gene (A and $\mathbf{C} \# \mathbf{1}$, \#2), compared with the normal growth on

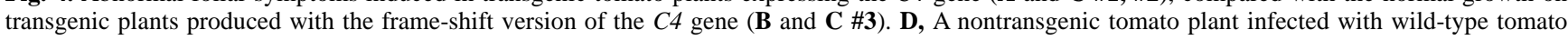
leaf curl geminivirus (TLCV). 
The result of Northern (RNA) blot analysis of the different $\mathrm{C} 4$ transgenic lines is shown in Figure 2A. There was virtually no detectable level of RNA in normal plants and the level of expression increased from the mildly abnormal plant (Fig. $1 \mathrm{~B}$ and Fig. 2, lane 8) to the most severely abnormal phenotype (Fig. 1A and Fig. 2, lane 16). These results showed a close correlation between the level of expression of the $C 4$ transgene and the appearance of viruslike symptoms in transgenic tobacco.

Transgenic plants showing symptoms were maintained under glasshouse conditions for over a year and were cut back after each flowering cycle. Following many cycles of growth and flowering, some of the abnormal plants were observed to produce some normal shoots. The $C 4$ transgene expression in normal and abnormal leaf tissues was compared (Fig. 2B). Expression of the $C 4$ transgene was virtually undetectable in the normal shoots, further correlating viruslike symptoms with expression of the $C 4$ transgene.

In order to examine whether the viruslike symptoms resulted directly from $C 4$ transcript per se, or resulted from the production of $\mathrm{C} 4$ protein, a modified $\mathrm{C} 4$ expression construct was produced containing a frame-shift mutation in the $\mathrm{C} 4$ ORF. A unique Csp45I site at nucleotide 2422 of TLCV was digested, end-filled with Klenow fragment, and blunt-end ligated to give pBSC4/F-S. Sequencing confirmed the insertion of 2 bases causing a frame-shift after amino acid 14 of the C4 ORF. The wild-type TLCV C4 ORF encodes a protein of 102 amino acids, while the frame-shift $\mathrm{C} 4$ mutant terminates after 44 amino acids, of which only the first 14 amino acids would be the same as the wild-type protein. Further subcloning steps into pJIT163, pBin19, and electroporation into $A$. tumefaciens strain LBA4404 were as described above.

A second round of transgenic tobacco plants was produced with the pBinC4 and pBinC4/F-S constructs. As before, abnormal phenotype plants were produced with the $\mathrm{C} 4$ gene construct. However, all lines produced with the $\mathrm{C} 4$ frame-shift construct appeared normal (Fig. 1C). Direct comparison of RNA expression from different abnormal C4 lines with normal C4 frame-shift lines showed comparable levels of transcription (Fig. 3). These results demonstrate that the $\mathrm{C} 4$ protein and not the $C 4$ RNA transcript induces viruslike symptoms in the abnormal transgenic tobacco plants.

Both the wild-type and the frame-shift $\mathrm{C} 4$ constructs were also used to produce transgenic tomato (Lycopersicon esculentum cv. Ailsa Craig). The transformation method used was essentially as described by Bird et al. (1988). Transgenic tomato plants expressing the $\mathrm{C} 4$ protein displayed viruslike symptoms similar to those observed in tobacco. These included smaller laminae with curling, twisting (Fig. 4A, 4C \#1 and 2) and enations on stems, petioles, and leaves. As in tobacco, all transgenic tomato plants produced with the frame-

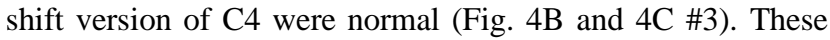
results confirm that the observed $\mathrm{C} 4$ transgenic phenotype was not due to a specific $\mathrm{C} 4$ protein-tobacco interaction.

It should be noted that the viruslike symptoms displayed by abnormal C4 transgenics of both tobacco (Fig. 1) and tomato (Fig. 4) are more severe than and differ from those normally associated with TLCV infection of these hosts (Fig. 1, compare A and B with D). This is not surprising, because the $C 4$ gene was expressed, not with its natural viral promoter and controlling elements, but under the control of the CaMV 35S promoter. Thus, $\mathrm{C} 4$ gene expression may not be limited only to cells normally invaded by the virus, but would be constitutively expressed in all tissues. The results presented here support the previous work of Rigden et al. (1994), who concluded that the C4 ORF of TLCV encodes a protein involved in symptom development.

Latham et al. (1997) have recently demonstrated the induction of abnormal tissue development in $N$. benthamiana plants expressing the $\mathrm{C} 4 \mathrm{ORF}$ of BCTV, showing a role for this protein in the regulation of host cell division. In line with their observations, we have also found that the TLCV C4 gene expression induces abnormal cell growth, including enation in our most severely abnormal transgenic lines. Thus, the C4 protein joins the list of other viral proteins, including the CaMV VI protein (Baughman et al. 1988), the BL1 protein from squash leaf curl geminivirus (Pascal et al. 1993), the p19 and p22 proteins of tomato bushy stunt virus (Scholthof et al. 1995), and the ORF0 protein of potato leafroll virus (van der Wilk et al. 1997), that have been shown to interfere with host metabolism, causing viruslike symptoms when expressed in transgenic plants.

It would be interesting to examine the phenotypic response of transgenic plants expressing the $\mathrm{C} 4 \mathrm{ORF}$ equivalent of bipartite geminiviruses. The function of the $\mathrm{C} 4 \mathrm{ORF}$ appears to be a character distinguishing monopartite and bipartite geminiviruses, and may provide a further clue to the evolution of geminiviruses.

\section{ACKNOWLEDGMENTS}

We thank John Randles for useful discussion, Phil Mullineaux for the gift of pJIT163, and Terri King and Jamus Stoner for technical assistance. This work was supported in part by Gene Shears Pty Ltd., and in part by the Department of Crop Protection, University of Adelaide.

\section{LITERATURE CITED}

Baughman, G. A., Jacobs, J. D., and Howell, S. H. 1988. Cauliflower mosaic virus gene $V I$ produces a symptomatic phenotype in transgenic tobacco plants. Proc. Natl. Acad. Sci. USA 85:733-737.

Bevan, M. 1984. Binary Agrobacterium vectors for plant transformation. Nucleic Acids Res. 12:8711-8721.

Bird, C. R., Smith, C. J. S., Ray, J. A., Moureau, P., Bevan, M. W., Bird, A. S., Hughes, S., Morris, P. C., Grierson, D., and Schuch, W. 1988. The tomato polygalacturonase gene and ripening-specific expression in transgenic plants. Plant Mol. Biol. 11:651-662.

Briddon, R. W., and Markham, P. G. 1995. Geminiviridae. Pages 158165 in: Virus Taxonomy. Classification and Nomenclature of Viruses. Sixth Report of the International Committee on Taxonomy of Viruses. F. A. Murphy, C. M. Fauquet, D. H. L. Bishop, S. A. Ghabrial, A. W. Jarvis, G. P. Martelli, M. A. Mayo, and M. D. Summers, eds. Springer-Verlag, Vienna.

Brough, C. L., Hayes, R. J., Morgan, A. J., Coutts, R. H. A., and Buck, K. W. 1988. Effects of mutagenesis in vitro on the ability of cloned tomato golden mosaic virus DNA to infect Nicotiana benthamiana plants. J. Gen. Virol. 69:503-514.

Dry, I. B., Rigden, J. E., Krake, L. R., Mullineaux, P. M., and Rezaian, M. A. 1993. Nucleotide sequence and genome organization of tomato leaf curl geminivirus. J. Gen. Virol. 74:147-151.

Elmer, J. S., Brand, L., Sunter, G., Gardiner, W. E., Bisaro, D. M., and Rogers, S. G. 1988. Genetic analysis of the tomato golden mosaic virus II. The product of the AL1 coding sequence is required for replication. Nucleic Acids Res. 16:7043-7060.

Etessami, P., Saunders, K., Watts, J., and Stanley, J. 1991. Mutational analysis of complementary-sense genes of African cassava mosaic virus DNA A. J. Gen. Virol. 72:1005-1012.

Guerineau, F., Lucy, A., and Mullineaux, P. 1992. Effect of two consen- 
sus sequences preceding the translational initiator codon on gene expression in plant protoplasts. Plant Mol. Biol. 18:815-818.

Hong, Y. G., and Harrison, B. D. 1995. Nucleotide sequences from tomato leaf curl viruses from different countries - evidence for three geographically separate branches in evolution of the coat protein of whitefly-transmitted geminiviruses. J. Gen. Virol. 76:2043-2049.

Hoogstraten, R. A., Hanson, S. F., and Maxwell, D. P. 1996. Mutational analysis of the putative nicking motif in the replication-associated protein (AC1) of bean golden mosaic geminivirus. Mol. PlantMicrobe Interact. 9:594-599.

Horsch, R. B., Fry, J. E., Hoffmann, N. L., Eichholtz, D., Rogers, S. G., and Fraley, R. T. 1985. A simple and general method for transferring genes into plants. Science 227:1229-1231.

Jupin, I., Dekouchkovsky, F., Jouanneau, F., and Gronenborn, B. 1994. Movement of tomato yellow leaf curl geminivirus (TYLCV) - involvement of the protein encoded by ORF C4. Virology 204:82-90.

Kheyr-Pour, A., Bendahmane, M., Matzeit, V., Accotto, G. P., Crespi, S., and Gronenborn, B. 1991. Tomato yellow leaf curl virus from Sardinia is a whitefly-transmitted monopartite geminivirus. Nucleic Acids Res. 19:6763-6769.

Latham, J. R., Saunders, K., Pinner, M., and Stanley, J. 1997. Induction of plant cell division by beet curly top virus gene C4. Plant J. 11: 1273-1283.

Laufs, J., Traut, W., Heyraud, F., Matzeit, V., Rogers, S. G., Schell, J., and Gronenborn, B. 1995. In vitro cleavage and joining at the viral origin of replication by the replication initiator protein of tomato yellow leaf curl virus. Proc. Natl. Acad. Sci. USA 92:3879-3883.

Navot, N., Pichersky, E., Zeidan, M., Zamir, D., and Czosnek, H. 1991. Tomato yellow leaf curl virus: A whitefly-transmitted geminivirus with a single genomic component. Virology 185:151-161.
Noris, E., Hidalgo, E., Accotto, G. P., and Moriones, E. 1994. High similarity among the tomato yellow leaf curl virus isolates from the West Mediterranean Basin: The nucleotide sequence of an infectious clone from Spain. Arch. Virol. 135:165-170.

Pascal, E., Goodlove, P. E., Wu, L. C., and Lazarowitz, S. G. 1993. Transgenic tobacco plants expressing the geminivirus BL1 protein exhibit symptoms of viral disease. Plant Cell 5:795-807.

Pooma, W., and Petty, I. T. D. 1996. Tomato golden mosaic virus open reading frame AL4 is genetically distinct from its $\mathrm{C} 4$ analogue in monopartite geminiviruses. J. Gen. Virol. 77:1947-1951.

Rigden, J. E., Krake, L. R., Rezaian, M. A., and Dry, I. B. 1994. ORF $\mathrm{C} 4$ of tomato leaf curl geminivirus is a determinant of symptom severity. Virology 204:847-850.

Sambrook, J., Fritsch, E. F., and Maniatis, T. A. 1989. Molecular Cloning: A Laboratory Manual. 2nd ed. Cold Spring Harbor Laboratory, Cold Spring Harbor, NY.

Scholthof, H. B., Scholthof, K. B. G., and Jackson, A. O. 1995. Identification of tomato bushy stunt virus host-specific symptom determinants by expression of individual genes from a potato virus $\mathrm{X}$ vector. Plant Cell 7:1157-1172.

Stanley, J., and Latham, J. R. 1992. A symptom variant of beet curly top geminivirus produced by mutation of open reading frame $\mathrm{C} 4$. Virology 190:506-509.

Sung, Y. K., and Coutts, R. H. A. 1995. Mutational analysis of potato yellow mosaic geminivirus. J. Gen. Virol. 76:1773-1780.

van der Wilk, F., Houterman, P., Molthoff, J., Hans, F., Dekker, B., van den Heuvel, J., Huttinga, H., and Goldbach, R. 1997. Expression of the potato leafroll virus ORF0 induces viral-disease-like symptoms in transgenic potato plants. Mol. Plant-Microbe Interact. 10:153-159. 